\title{
Sentir e inteligir en Husserl y Zubiri
}

\author{
José Alfonso Villa Sánchez \\ Universidad Michoacana de San Nicolás de Hidalgo
}

Resumen

El carácter problemático de la esencia del sentir, de la esencia del inteligir y del modo como ambos se relacionan en el proceso del conocimiento está presente a lo largo de la historia de la filosofía. La crítica de Xavier Zubiri es que este problema ha sido tratado, desde Platón hasta Husserl, de manera dicotómica. Su tesis es que debe tratarse a la sensibilidad y a la inteligencia como una realidad estructural. En este texto damos cuenta del modo como Husserl se acercó a este antiguo problema, mostramos el tratamiento dicotómico que hay del asunto en sus investigaciones e iniciamos un contraste con la tesis de Zubiri en el sentido de que el sentir y la inteligencia conforman una sola estructura, la inteligencia sentiente.

Palabras clave: Husserl, Zubiri, sensibilidad, inteligencia, razón, conciencia intencional, inteligencia sentiente.

\section{Abstract}

The problematic nature of the essence of feeling, the essence of intellection and the way of how both relate each other in the knowledge process is present through the history of Philosophy. Xavier Zubiris critique is that this issue has been managed, from Plato to Husserl, in two different perspectives. His theory is that sensibility and intel- 
ligence have to be managed as an structural reality. In this text, we account for the way Husserl reached this old issue, show his dichotomy about this matter in his investigations and we show a contrast with Zubiri's thesis in the sense that feeling and intelligence make up one only structure, the sentient intelligence.

Keywords: Husserl, Zubiri, sensibility, intelligence, reason (reasoning), intentional conscience, sentient intelligence.

\section{Planteamiento del problema}

T a "relación" entre el sentir y el inteligir ha sido uno de los Lgrandes problemas en la historia de la filosofía. Desde Platón, antes ya con los pitagóricos de quienes lo hereda, "hasta Husserl. Los debates interminables a lo largo de la historia de este problema tratan sobre la esencia de lo que sea el sentir, sobre la esencia de lo que sea el inteligir y sobre la manera como estas dos dýnamis, potencias o facultades, se relacionan. Las escuelas y las corrientes filosóficas diferenciaron sus posturas en los modos como matizaron la conceptualización de estas facultades y en la manera como conceptualizaron su relación y la función de cada una respecto de la otra. En Husserl tenemos una posición fenomenológicamente muy acabada en la conceptualización de este problema. Sin embargo, tenemos en su descripción una postura que se ciñe a la tradición en cuanto sigue distinguiendo en el hombre el momento de la sensibilidad del momento de la inteligibilidad: la sensibilidad tiene un momento de protosensibilidad que no tiene nada de razón. Y sin embargo, esa protosensibilidad, según Husserl, llegará a ser sensibilidad intelectual y razón sensible, para culminar en una razón primigenia. ¿Cómo sucede que una protosensibilidad, estrictamente hylética, llega a ser algo que no era: sensiblidad intelectual? Además del prejuicio de la tradición de que la sensibilidad y la inteligencia pueden y deben ser descritas primero de manera 
independiente, se cuela en las investigaciones de Husserl el prejuicio de que la sensibilidad y la inteligencia en el hombre se relacionan. En este punto es donde las investigaciones de Xavier Zubiri sobre el problema se vuelven relevantes y pertinentes. Su tesis es que en el hombre la sensibilidad y la inteligencia conforman una sola estructura a la que llama inteligencia sentiente. La sensibilidad humana ya siempre está preñada de inteligencia; y la inteligencia humana ya siempre está preñada de sensibilidad. Cuando se describe la inteligencia se está describiendo también, por la fuerza de las cosas mismas, la sensibilidad. Lo mismo al contrario: cuando se describe la sensibilidad humana se describe también su inteligencia. Zubiri se ha apropiado de este problema sobre la sensibilidad y la inteligencia en los modos como la tradición lo trató. Pero remonta el tratamiento tradicional cuando explica filosóficamente, de modo decisivo, que se trata de una estructura y no de la relación de dos facultades.

En la primera parte de este texto exponemos con cierto detalle la postura de Husserl, ya que representa de forma muy refinada y exigente el modo como se trató el problema en la tradición y el modo como se le resolvió. Además de que Zubiri se sabe discípulo de Husserl y es con él con quien discute, en alguna medida, su propuesta de la inteligencia estructuralmente sentiente ${ }^{1}$. La postura de Zubiri, en diálogo con Husserl, la exponemos a continuación de la de Husserl.

${ }^{1}$ Sobre Husserl y Zubiri se puede sacar gran provecho del estudio de Víctor Manuel Tirado San Juan, intitulado Intencionalidad, actualidad y esencia: Husserl y Zubiri, Publicaciones Universidad Pontificia de Salamanca, 2002. Se trata de una muy completa y rigurosa exposición del pensamiento de Husserl en su primera mitad y de una exposición de igual calidad respecto del pensamiento de Zubiri en la segunda. Falta, sin embargo, el momento de la discusión entre ambos filósofos sobre algunos de los temas en los que Zubiri continúa a Husserl conforme a sus propias perspectivas. 


\section{Husserl: la razón sumergida en sensibilidad}

El método de la reducción fenomenológica puso a Husserl frente a la conciencia intencional. Describirla en su puro darse fenomenológico era una empresa no menor que la que llevó a su descubrimiento. Por uno de sus polos, por decirlo así, la vivencia intencional da al yo puro en tanto origen de toda conciencia y de toda intencionalidad; por el otro de sus polos la conciencia apunta hacia lo dado en la sensibilidad. Así aparecía de vuelta el añejo problema moderno sobre el papel de los sentidos y el de la razón en eso que sea el conocimiento.

\section{a) Los momentos de la conciencia}

Una de las cruces ${ }^{2}$ ancestrales de la filosofía es la que se refiere al papel que juegan los sentidos, por un lado, y la inteligencia, por otro, en eso que, sin mayores compromisos por ahora, llamaré el conocimiento. Es un problema del que la filosofía moderna se hizo cuestión de modo radical (Descartes, Hume, Kant) pero que se remonta a la Edad Media y hasta Aristóteles, Platón y Parménides. Es, pues, un problema que Husserl simplemente no puede pasar por alto. Una vez acotado el ámbito de la conciencia intencional como ámbito estrictamente fenomenológico en el que se juega la partida de la filosofía, la pregunta por el papel de lo sensible y el papel de lo inteligible no se hace esperar. Si bien la desustancialización de la conciencia es obligada a la altura de estos tiempos, el precipitado vivencial que ella es debe ser analizado en los momentos que fenomenológicamente le conforman. $\mathrm{Y}$ aunque se trate de

\footnotetext{
${ }^{2}$ El análisis de la conciencia del tiempo es también una de esas cruces de la filosofía, según el propio Husserl. Cfr. Husserl, Lecciones de fenomenología de la conciencia interna del tiempo, Agustín Serrano de Haro (trad.), Madrid, Trotta, 2002, p. 25.
} 
un precipitado vital (¡o precisamente por ello?), hay unos ingredientes hyléticos, sensibles, materiales, que conforman la conciencia; y unos ingredientes noéticos, cuyos orígenes son distintos a los primeros. De dónde vienen estos diversos ingredientes y cómo es que se precipitan vital-conciencial-intencionalmente es lo que queremos aclararnos.

Voy a acercarme con sumo cuidado al $\$ 85$ de Ideas I intitulado «ulh sensible, morf» intencional» (Husserl, 1995: 202-207), pues en él aparece, por un lado, esta distinción fenomenológica de los dos momentos de la conciencia y, por otro, todo lo cerca que Husserl está de tematizar el "de algo" de la "conciencia de" que remite irrefragablemente a un alter respecto de la conciencia intencional, que pide también un acercamiento riguroso, pero que Husserl no hace.

La intencionalidad de la conciencia, dice Husserl, "se asemeja a un medio universal que encierra en sí todas las vivencias, incluso aquellas que no se caracterizan como intencionales" (1995: 202). En lo más puro de su línea de investigación, el fenómeno por antonomasia es la intencionalidad de la conciencia. Repárese en que esta conciencia intencional está recogiendo desde ya, en lo que le constituye, unas vivencias que propiamente, y abandonadas a sí mismas (si esto pudiera ser posible tratándose de la conciencia), no son propiamente intencionales; sin embargo, a esas vivencias no intencionales la intencionalidad les viene dada por la conciencia. Conciencia e intencionalidad constituyen una misma cosa: la conciencia de. En una investigación de fenomenología pura hay que abstenerse de pretender "descender a las oscuras profundidades de la conciencia última que constituye la temporalidad de todas las vivencias" (Husserl, 1995: 202). En una investigación de fenomenología pura hay que tomar la temporalidad de todas las vivencias intencionales "según se ofrecen, como procesos temporales unitarios en la reflexión inmanente” (Husserl, 1995: 202). ¡Hay que ir 
directamente a las vivencias intencionales en la temporalidad de su ofrecimiento! En esas vivencias intencionales que se ofrecen como procesos temporales unitarios hay que distinguir dos momentos: su momento hylético y su momento noético. Sería un contrasentido tanto que la conciencia intencional surgiera absolutamente de ella misma (idealismo) como que surgiera absolutamente de lo dado a ella (materialismo). Es así, pues, que la conciencia debe tener un estrato hylético-noemático y un estrato noético.

Al momento hylético de las vivencias intencionales Husserl dice que "pertenecen ciertas vivencias por sumo género unitarias y "sensibles", los "contenidos de la sensación", como datos de color, datos de sonido, datos del tacto, etc., que ya no confundiremos con las notas de las cosas que aparecen, el color, la aspereza, etc., sino que, antes bien, se "exhiben" vivencialmente por medio de aquellos datos" (Husserl, 1995: 203).

Las vivencias intencionales en tanto que procesos temporales unitarios arrancan, parten, inician, en cierto modo, de unas vivencias "unitarias" y "sensibles"; unitarias y sensibles no de cualquier modo: "por su sumo género". Se trata de los contenidos de la sensación. Esos contenidos de la sensación, ulh de la vivencia intencional, son: datos (datum) de color, datos (datum) de sonido, datos (datum) del tacto. Estos contenidos de la sensación, esta $u$ lh de la vivencia intencional, no son ya propiamente el color, el sonido, el tacto mismos sino lo dado (datum) por el color, por el sonido, por el tacto como materia a la vivencia intencional. En tanto que data (datos), "ya no confundiremos [los contenidos de la sensación] con las notas de las cosas que aparecen, el color, la aspereza, etc., sino que, antes bien, se 'exhiben' vivencialmente por medio de aquellos datos" (Husserl, 1995: 203).

Husserl no trató fenomenológicamente los contenidos de la sensación en tanto que notas de las cosas que aparecen; esos contenidos de la sensación en tanto que notas de las cosas que aparecen 
como irrefragablemente altera respecto de la vivencia intencional, aunque sólo en la vivencia intencional, fueron tomados por Husserl como "datos de..., para" la vivencia intencional, como lo dado del color, lo dado del sonido, lo dado del tacto, dislocándolo del origen de su ser dado, dislocando al dato (datum) de su esencial carácter notificante de alteridad respecto de la conciencia. Si en los análisis de la vivencia intencional, que arranca con los contenidos de la sensación, se los tematiza en tanto que "datos de... para la conciencia de...", dislocándolos de su carácter de notas, dichos análisis volverán la cara hacia una fenomenología de la conciencia pura. Pero si los análisis tematizan a una los contenidos de la sensación en tanto que datos y en tanto que notas que notifican las cosas mismas que aparecen, habrá de ir a pararse también a cosas que son otras que la conciencia, pero no más allá de ella; que son otras que la conciencia, pero en ella. Habrá de ir a pararse, pues, a la realidad. Fue el camino de Zubiri en la fenomenología: la inteligencia sentiente frente a la conciencia intencional, y la realidad que se nota de suyo frente a los simples datos de color, sonido, tacto, etc.

Pero Husserl dice más sobre ese momento hylético de las vivencias intencionales: dice que los contenidos de la sensación, lo sensible, "en sí no tiene nada de intencionalidad" (Husserl, 1995: 203). Los "datos concretos" de lo sensible aparecen "como componentes de vivencias concretas más amplias que en conjunto son intencionales" (Husserl, 1995: 203). Respecto del carácter intencional de la conciencia, pues, los contenidos de la sensación son intencionalmente neutros. La intencionalidad les viene de otro lado. Fenomenólogo riguroso y todo, Husserl tiene que echar mano de una comparación para hacerse entender: "sobre esos elementos sensibles hay una capa, por decirlo asi, 'animadora', que les da sentido (o que implica esencialmente un darles sentido), capa mediante la cual se produce de lo sensible, que en sí no tiene nada de intencio-

\footnotetext{
${ }^{3}$ Las cursivas son mías.
} 
nalidad, justo la vivencia intencional concreta" (1995: 203). De modo que la intencionalidad la pone el yo, pero sobre los datos concretos que aportan los contenidos de la sensación. Esos datos son animados por una capa distinta a ellos que les da sentido. "Las vivencias intencionales se presentan como unidades en virtud de la operación de dar sentido [...] Los datos sensibles se dan como materia para conformaciones intencionales u operaciones de dar sentido en diversos grados [...]" (Husserl, 1995: 203).

La tesis de Husserl es que el momento hylético del precipitado vital que es la conciencia intencional da, aporta, un material a la conciencia que no lleva ni brizna de intencionalidad. ¿Pero es que acaso no es la conciencia toda intencional? Sí que lo es. Pero la intencionalidad le viene dada a toda la conciencia de su momento noético: este momento es el ánima de los elementos sensibles intencionales que conforman, por derecho propio, esta alegría, este triunfo o aquella derrota. ¿Sería posible una vivencia intencional meramente hylética y noemática? Absolutamente no. Porque por ser intencional es noética y por ser vivencia es hylética. A más de que toda vivencia intencional es siempre concreta. La comparación de la capa noética que anima los elementos sensibles no es muy precisa (no tiene porque serlo; es una comparación) porque siempre deja lugar para introducir distinciones peligrosas que pueden acabar en separar lo noemático de lo noético.

Además del imprescindible momento hylético, las vivencias intencionales tienen un momento noético, que nombra a la conciencia por su acepción más específica, porque es el que hace que la conciencia sea conciencia y sea precisamente intencional. El momento noético de la conciencia es la causa formal, intrínseca, de ese precipitado que es la vivencia intencional. En tanto que morf” de la conciencia, ella aporta a la ulh sensible la intencionalidad. La nóesis es la que da la forma intencional a las vivencias conformadas con materias sensibles no intencionales. Las materias sensibles 
sólo son materias sensibles; ellas solas no dan siquiera, ni hacen, conciencia; muchísimo menos conciencia intencional. La forma, en cambio, es la que hace y da conciencia. Ella es la que califica, propiamente, a la conciencia. Así, se puede decir que conciencia es igual a nóesis; pero no se puede decir que conciencia sea igual a nóema. Sin embargo, entiéndase bien, recordando al viejo Aristóteles, que resuena aquí con claridad, que aunque sea la forma la que determina esencialmente a lo que es, no lo hace sino en la concreción individual de su propia materia, en las materias sensibles en el caso de la conciencia intencional. En el rigor de los términos fenomenológicos de Husserl, nóesis es igual a conciencia intencional. Ya nos ha sido dicho también que, en el mismo rigor, no nos está dado tampoco hacer de lo dado a la conciencia cualidades objetivas de las cosas del mundo más que recurriendo a semejanzas desde la reflexión. La conciencia intencional, por lo tanto, ya en su momento noemático, pero sobre todo en su momento noético, no es del mundo; su origen no está en él. La audaz afirmación de Husserl al respecto es la siguiente: "el ser de la conciencia, de toda corriente de vivencias en general, quedaría sin duda necesariamente modificado por una aniquilación del mundo de las cosas, pero intacto en su propia existencia" (Husserl, 1995: 112).

El yo puro que es la conciencia intencional está conformado tanto por el momento hylético como por el momento noético; sin embargo, es el momento noético el que califica formalmente a la conciencia, lo único que queda en toda reducción trascendental, incluida la hipótesis de la aniquilación del mundo. "De hecho dice Husserl—, el yo puro no es otro, en efecto, que aquel que DESCARTES captó con mirada genial en sus magníficas meditaciones y estableció como tal para siempre, sobre cuyo ser no es posible ninguna duda, y que en toda duda volvería él mismo a encontrarse necesariamente como sujeto de la duda" (1997: 139). 
¿Qué hace, formalmente, el momento noético de la vivencia intencional? El momento noético de la vivencia intencional es el que especifica "el nus en el sentido más amplio de la palabra" (Husserl, 1995: 205). La conciencia intencional, toda ella, es decir, también su momento hylético, es nus; sin embargo, lo que formalmente la hace ser nus es su momento noético. Y este nus, en tanto noésis, vive formalmente en cogitationes que son vivencias intencionales. Éste es el punto donde el afán de distinguir en el torrente de las vivencias unitarias sus dos momentos se vuelve imposible. Sin embargo, puesto que el esfuerzo debe hacerse, dice Husserl que la nóesis "abarca todo aquello (y en esencia sólo aquello) que es un supuesto eidético de la idea de norma” (1995: 205). Descartes tiene razón respecto a que la vida noética del yo puro no le viene dada, en última instancia, a la conciencia intencional por las materias sensibles; la vida noética del yo puro consiste en el irrebasable ejercicio de la cogitatio. Hasta cabe la posibilidad de que, aniquilado el mundo, el ser de la conciencia quedara modificado, pero intacto en su existencia. La conciencia intencional es la que significa al mundo. Por eso su condición de posibilidad no puede ser el mundo. Al contrario, es ella la que lo constituye, es ella la que da significado a lo que sea el mundo. El dato fenomenológico en el que hay que saber detener la marcha es el del cogito que, en el límite, con evidencia, duda que duda, quiere que quiere, etc. Las "formas de vida actuales [de la conciencia intencional en tanto nóesis] nos retrotraen a cogitationes [...]" (Husserl, 1995: 205). La conciencia intencional en tanto conciencia noética es acto, no potencia. La posibilidad de la intencionalidad le viene dada a las materias sensibles por las formas de vida actuales de la conciencia que son las cogitationes que ella ya siempre es y que no le vienen del mundo. Lo que formalmente define, pues, a la conciencia intencional es su momento noético. La vivencia intencional es toda ella nus; pero lo es, sin ninguna duda, por su momento noético. Y 
"no deja de ser bienvenido el que la palabra nus recuerde en una de sus más señaladas significaciones justamente 'sentido"” (Husserl, 1995: 205). Este dato lingüístico extra abona para la comprensión de la esencia de la conciencia en tanto dadora y originadora del sentido: "aunque el 'dar sentido' que se lleva a cabo con los elementos noéticos tiene un variado alcance y sólo por fundamento un 'dar sentido' que se vincula al concepto plenario de sentido" (Husserl, 1995: 205).

La intencionalidad de la conciencia no viene dada, pues, por las materias sensibles sino por la misma conciencia; pero desde las materias sensibles. El precipitado, en definitiva, que es la conciencia intencional está conformado por el material sensible del momento hylético y por el sentido de su momento noético. "La corriente del ser fenomenológico tiene una capa material y una capa noética" (Husserl, 1995: 205).

\section{b) La estructura de la conciencia}

Acabamos de pasar revista a la conciencia intencional desde el punto de vista de los dos momentos, el noético y el noemático, que conforman el precipitado que es toda vivencia intencional. Es una perspectiva, por decirlo así, horizontal de la conciencia. Ahora vamos a llevar a cabo un acercamiento a la vivencia intencional desde una perspectiva vertical: desde su estrato más alto hasta su estrato más bajo. La conciencia intencional, el yo puro, el espíritu, que no es del mundo sino que lo significa, tiene "un subsuelo anímico" (Husserl, 1997: 385). Es aquí la tesis de Husserl: que hay un subsuelo, un suelo y un suprasuelo en la conciencia.

¿En dónde está la mostración fenomenológica de este subsuelo anímico del espíritu, de esta estratificación de la conciencia? Así responde Husserl: 
en que el sujeto yo no tiene que atenerse a meras retenciones y reproducciones de recuerdo. La reproducción sensible gobierna también de tal forma que en circunstancias sensiblemente similares emerge lo similar, y por ende la similitud sensible actúa haciendo nacer nuevas predaciones de especie sensiblemente similar a las que antes se originaron productivamente, y entre ellas hay algunas que pese a esta similitud (y justo porque esta similitud es con frecuencia precisamente una similitud meramente "externa"sensible) no pueden convertirse al estado de la primigenidad (1997: 385-386).

Husserl no tiene fenomenológicamente ninguna duda de que "el espíritu tiene un subsuelo anímico”. Anímico refiere a animado, a animal; ${ }^{4}$ y animado, animal, refiere a sensibilidad. Las frases siguientes del párrafo que citamos no dejan lugar a dudas. Si el espíritu no tuviera ese subsuelo anímico viviría de meras retenciones y de meras reproducciones de recuerdo. Pero esto sería absurdo de principio porque ¿de dónde va a sacar el sujeto yo los recuerdos a fin de reproducirlos y de dónde va a sacar aquello que debe ser retenido? De sí mismo desde luego que no. Tal cosa sería idealismo. Y Husserl no es un idealista. Por lo menos no lo es de este modo. ¿Dónde está, pues, el origen primigenio de lo recordado para ser reproducido y de lo retenible para ser retenido? En la reproducción sensible; y conforme a la siguiente ley: "en circunstancias sensiblemente similares emerge lo similar" (Husserl, 1997: 385). El motor de la reproducción sensible que da para la posibilidad de reproducciones de recuerdo y de las meras retenciones es la similitud sensible que, dice Husserl, "actúa haciendo nacer nuevas predaciones de

\footnotetext{
${ }^{4}$ Así comenta Antonio Zirión al respecto, en su presentación de Ideas II: "según el modo como Husserl usa estos términos, lo animal [tierisch] comprende sólo a los brutos (los animales [Tiere]), no al hombre; pero el hombre es, sin embargo, junto con todos los animales, un animal [Animal], un ser 'animado'” (Husserl, 1997: 15).
} 
especie sensiblemente similar a las que antes se originaron productivamente" (Husserl, 1997: 385-386). De modo que lo predado para que el espíritu lleve a efecto reproducciones de recuerdo y meras retenciones remontan a la similitud en la reproducción de la sensibilidad. Tal recuerdo o tal retención subjetiva remonta a una tal predación sensible más de una vez. Del espíritu, sus reproducciones de recuerdo y sus retenciones, al ánima, a sus reproducciones sensibles, a la similitud sensible y hasta sus predaciones. Y de estas reproducciones sensibles, similitudes sensibles y predaciones, a la sensibilidad misma, ese subsuelo anímico, pero oscuro, del espíritu. Husserl nos dibuja el siguiente mapa de los estratos de la conciencia: "Distinguimos SENSIBILIDAD y [...] RAZÓn. En la sensibilidad distinguimos PROTOSENSIBILIDAD, que no contiene nada de sedimentos de razón, y la sensibilidad secundaria, que nace de una producción de la razón. En conformidad con ello dividimos también la razón en RAZÓN PRIMIGENIA, INTELLECTUS AGENS, y razón sumergida en la sensibilidad" (1997: 386). ${ }^{5}$ El flujo que es la conciencia es cooriginariamente protosensibilidad y razón primigenia, sensibilidad secundaria y razón sumergida en sensibilidad: razón sentiente.

Advertidos de esta cooriginariedad, "hablemos ahora sobre la sensibilidad” (1997, 386), invita Husserl. ¿Qué es la sensibilidad en general? Es "el subsuelo anímico del espíritu, y del espíritu en

${ }^{5}$ He aquí un esquema del párrafo:

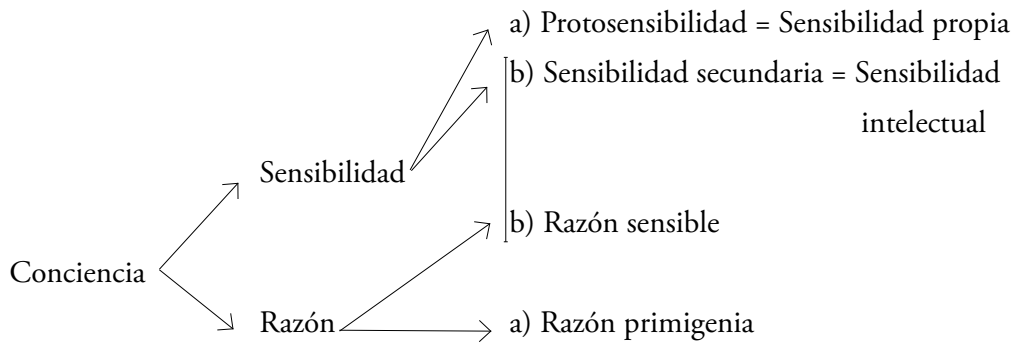


todos los niveles concebibles, o el subsuelo de los actos del espíritu en todos los niveles concebibles [...]" (Husserl, 1997: 386).

Los niveles concebibles, grosso modo, del espíritu son dos. Tenemos, en primer lugar, los niveles ínfimos de los actos del espíritu: aquí "nos sirve de ilustración el acto simple de irradiar la mirada espiritual a algo que afecta al sujeto, delimitándolo en el tiempo, apresándolo, considerándolo [...]" (Husserl, 1997: 386). El que ve, el que delimita, el que apresa, el que considera, etc., no es el ojo; el que opera todos estos actos es el espíritu, el sujeto. Y, sin embargo, no lo hace más que irradiando la simple mirada, operando un acto que parecería de lo más inofensivo por pertenecer a la obviedad de los actos mecánicos del cuerpo. Sirve también de ilustración para este nivel de los actos ínfimos del espíritu "el simple volverse en el agrado activo" (Husserl, 1997: 380) en el que el espíritu se encuentra gustosamente a modo porque la temperatura, la luz, el sonido, la comida o la bebida le envuelven placenteramente. El agradado no es el oído, o el ojo o el paladar. El agradado, en estos niveles ínfimos de los actos de la conciencia, es precisamente el espíritu.

Pero la sensibilidad es, en segundo lugar, también subsuelo anímico de "los actos supremos de razón" (Husserl, 1997: 383): de los actos supremos de razón en el pensamiento teórico, en la creación artística y en la actuación ético-social. Sin embargo, la imbricación entre estos actos superiores de la razón y la sensibilidad, específicamente de la sensibilidad secundaria, debe esperar hasta después de fijar la mirada en la protosensibilidad, el estado ínfimo de ese subsuelo anímico que es la sensibilidad.

¿Qué es, pues, la protosensibilidad? Husserl escalona su protocomposición del siguiente modo: a) El nivel ínfimo lo conforman diversos data (datum: lo dado, dato): "los datos sensibles, los datos de color en su campo visual de sensación” (1997: 386), los datos táctiles, los datos auditivos, los datos cinestésicos. La protosensibilidad, en su estado ínfimo, es la unidad de estos 
diversos data. No se trata de la unidad de una apercepción. ${ }^{6}$ Se trata de la unidad de lo dado en la protosensibilidad, anterior a toda apercepción, aunque, como indica Husserl, "también después de ella puede ser hallado como momento de una apercepción" (Husserl, 1997: 386), sea del aspecto visual, auditivo, táctil, etc. b) También en el nivel ínfimo están otro tipo de datos: los datos sensibles del impulso en tanto que protovivencias y, por tanto, "siempre pertenecientes a la composición del subsuelo anímico" (Husserl, 1997: 386). No se trata de los impulsos en tanto que cosas trascendentes a la conciencia y objeto, entonces, de las ciencias de la naturaleza o de la psicología.

La sensibilidad en general (por tanto también la protosensibilidad y la sensibilidad secundaria) funciona conforme a unas leyes propias. Las leyes de hecho de la sensibilidad son la asociación y la reproducción. Esta puede ser por recuerdo, fusión o fantasía. Estas leyes regulan, no la esencia de la sensibilidad, sino la sensibilidad misma en tanto que hecho: la asociación y la reproducción son "reglas de una cuasiproducción de sensibilidades siempre nuevas" (Husserl, 1997: 380) que, sin embargo, no se originan en la razón; pero que en tanto que la asociación y la reproducción son cuasiproductoras de sensibilidades siempre nuevas, el recuerdo, la fusión y la fantasía, por ejemplo, son ya del ámbito de la sensibilidad secundaria, subrayando que su reproducción no emana de la razón. Pero apunta, irrefragablemente, a ella. Por este motivo dice Husserl que "quizá sería terminológicamente mejor distinguir entre sensibilidad propia" (Husserl, 1997: 386) o sensibilidad sin espíritu, por un lado, y sensibilidad impropia o intelectiva-espiritual.

${ }^{6}$ Heidegger piensa, y esto vale también contra Zubiri, que la "simplicidad" de una "pura percepción" carece de los "respectos remisionales explícitos (del paraqué) que son propios de la totalidad respeccional a partir de la cual queda comprendido lo simplemente compareciente" (Heidegger, [Ser y tiempo] p. 173) en una visión comprensora-interpretante. 
Hay una pregunta que nos sale al paso obligadamente: ¡en dónde nace la sensibilidad intelectiva secundaria? El proceso es el siguiente. La asociación y la reproducción pertenecen no sólo a la esencia de toda vivencia sensible, sino también a la esencia de toda vivencia de los actos supremos de la razón tales como el pensamiento teórico, la creación artística y la actuación ética. Tan pronto como estos actos supremos de la razón existen actúan asociativamente: "se someten a la ley de la retención y están bajo las condiciones del recuerdo, de la transformación, de la eficacia para la producción de fantasías similares, etc.” (Husserl, 1997: 387). Aquí ha nacido la sensibilidad intelectiva secundaria. Ya sabemos que recuerdo, fusión, fantasía (reproducción) y todo tipo de asociación remiten de suyo a datos de las protovivencias de la protosensibilidad. Y ésta, dice Husserl, "no se origina por asociación. La protosensibilidad, la sensación, etc., NO nace A PARTIR DE BASES INMANENTES, de tendencias anímicas; ella está simplemente ahí, se presenta" (Husserl, 1997: 387). Aquí es donde lo fenomenológicamente dado, en sentido estricto, tiene su límite, más allá de lo cual no nos es dado ir más que con otro método.

Podría pensarse, entonces, que todo acto intelectivo tendría sus orígenes más remotos en la protosensibilidad. ¿O acaso podría ser de otro modo? ¡Es de otro modo! Por lo menos así lo piensa Husserl. "Lo protointelectivo tampoco nace 'anímicamente' a partir de asociaciones, sino a partir de irradiación desde el yo, que no está ahí (como lo ajeno al yo), sino que es precisamente absoluto" (Husserl, 1997: 387).

Antes de que sean dadas la protosensibilidad y la sensibilidad secundaria, y para que pueda darse toda sensibilidad, hay el yo absoluto, se da el yo absoluto. "El yo espiritual es punto de referencia para todo, el yo que se refiere a todo lo espacio-temporal, pero él mismo no está en el tiempo y en el espacio" (Husserl, 1997: 402). Si hay sensibilidad es porque hay yo absoluto. Por un lado, el yo 
absoluto no pende de ninguna manera de la sensibilidad; pero, por otro lado, "el yo presupone la sensibilidad como afección, como estímulo..." (Husserl, 1997: 387). En este sentido, el yo tiene siempre un hábitus que es su protohaber: la protosensibilidad. Es el nivel ínfimo de todo acto (si pudiera hablarse aquí de acto), preñado por la ausencia de toda intencionalidad. Husserl habla de Una "PROTOESFERA DE LA SENSIBILIDAD, DE UNA INTENCIONALIDAD IMPROPIA porque no se habla de una propia 'intención a', para lo cual es menester el yo" (Husserl, 1997: 387).

La protosensibilidad es esfera de una "cierta" pasividad. Pero no es la protosensibilidad una pasividad absolutamente pasiva, por decirlo de alguna manera. Porque esa pasividad de la protosensibilidad del yo absoluto está ya cualificada para la intencionalidad de ese yo: la "representación de", la apercepción, ya están en la pasividad de tal protosensibilidad. El carácter activo de la protosensibilidad en tanto que pasividad está determinado por su receptividad: esta es la ínfima actividad de la conciencia absoluta en tanto que protosensibilidad pasiva. En resumen:

Tenemos, pues, en la esfera de las vivencias el gran campo de la sensibilidad primaria con su enrejado de nexos tendenciosos, con sus constituciones objetivas, con sus regulaciones que se formulan por el tema: aparece un mundo objetivo y susceptible de ser mantenido concordantemente. Y en ello imperan leyes primitivas, digamos de la asociación y la reproducción, según las cuales nacen "representaciones" con la inferior y más primigenia intencionalidad; toda reproducción tiene su intencionalidad (Husserl, 1997: 388).

3. Zubiri: la inteligencia estructuralmente sentiente.

Desde la filosofía primera de Zubiri se presenta como muy problemática esta postura de Husserl en la cual la sensibilidad y la razón, 
teniendo en su raíz orígenes distintos, vengan a encontrarse sólo posteriormente para realizar un solo acto siendo dos momentos distintos. La explicación de Husserl no parece satisfactoria. Así que habrá que intentar, desde Husserl y con Husserl, otros caminos.

\section{a) La inteligencia sentiente como acto}

Zubiri piensa que en lo relativo a la inteligencia sentiente también ha de recorrerse la vía de la descripción física, desde el principio. Sólo así se podrá mostrar que eso que es inteligir es mera actualización de lo real en el nous, y no intencionalidad de la conciencia. Es por eso que hay que volver la mirada hasta Aristóteles. Es verdad que sentir e inteligir son dos potencias, dynamis: el hombre puede sentir y puede inteligir (Cfr. Aristóteles, 2000: 416b33-418a5; 430a10-b30). Pero el propio Zubiri advierte que la idea aristotélica de la dynamis, del poder, es muy rica, especialmente por lo que hace al sentir y al inteligir. Así, uno de los significados de dýnamis es potencia: "ya desde Aristóteles dýnamis significa potencia, aquello según lo cual algo puede recibir actuaciones o actuar desde sí mismo no sólo sobre algo distinto del actuante, sino también sobre el actuante mismo, pero en tanto que distinto de su actuación" (Zubiri, 1998: 89).

Empecemos por resaltar esa idea de que dýnamis se dice de varias maneras. En el capítulo decimosegundo del Libro V de la Metafísica Aristóteles indica los diversos modos de dýnamis:

“ $\langle 1\rangle$ Se llama "potencia” o "capacidad" $\langle a\rangle$ el principio del movimiento o del cambio que se da en otro, o bien 〈en lo mismo que es cambiado, pero en tanto que otro: por ejemplo, el arte de edificar es una potencia que no se da en lo que es edificado, mientras que el arte de curar, siendo potencia, puede darse en el que es curado, pero no en tanto que es curado. En general, pues, se llama potencia o capacidad: de una parte, el principio del cambio o del 
movimiento que se da en otro, o bien 〈en lo mismo que es cambiado), pero en tanto que otro; de otra parte, 〈el principio según el cual algo es cambiado o movidoñ por la acción de otro, o bien $\langle$ en lo mismo que es cambiado o movido〉 por la acción de otro, o bien 〈de aquello mismo, pero en tanto que otro (en efecto, de lo que padece decimos que es "capaz de" padecer en virtud de aquel principio según el cual padece alguna afección, bien se trate de una afección cualquiera, bien se trate no de cualquier afección, sino para mejor). 〈b $\rangle$ Además, la capacidad de realizar algo perfectamente o según la propia intención. A veces decimos, desde luego, que no son capaces de hablar o de andar quienes meramente hablan o andan sin hacerlo perfectamente o como querrían. Y de modo semejante en el caso del padecer. $\langle c\rangle$ Se llaman, además, potencias todas aquellas cualidades poseídas por las cosas en cuya virtud éstas son totalmente impasibles, o no se dejan cambiar fácilmente para peor. Y es que las cosas se rompen, se quiebran, se doblan y, en general, se destruyen, no por su potencia, sino por su impotencia y porque les falta algo. Por el contrario, son impasibles aquellas cosas que padecen difícilmente, o apenas, en virtud de su potencia, en virtud de que son potentes y poseen ciertas cualidades (Aristóteles, 1994: 1019a15-32) ${ }^{7}$.

En tanto que potencia, dýnamis se dice, pues, de dos: a) en primer lugar, potencia se dice de aquello según lo cual algo puede recibir actuaciones (potencia pasiva. Cfr. Aristóteles, 1994: 1046a11); b) en segundo lugar, dýnamis en tanto que potencia se dice de aquello que puede actuar desde sí mismo; y esto de dos modos: 1) puede actuar sobre algo distinto del actuante y 2) puede actuar sobre el actuante mismo, con una condición: que lo haga en tanto distinto de su actuación (1994: 1029a5). Es preciso dibujar de modo

${ }^{7}$ La versión citada es la de Tomás Calvo. En su primera acepción dýnamis se refiere a potencia, en la segunda a capacidad y en la tercera a cualidades. $\mathrm{Zu}$ biri se refiere a dýnamis en tanto potencia. Cfr. también 1046a35-1046b25; 1047b30-1048a24. 
conceptualmente riguroso esta distinción sobre la naturaleza de la dýnamis en tanto que potencia. La necesitaremos a la hora de ceñir la inteligencia sentiente.

Cuando los latinos tradujeron dýnamis como "potentia seu facultas", potencia o facultad, la matizaron de tal modo que la dicotomía entre el poder de sentir y el poder de inteligir quedó consagrada ${ }^{8}$. Para empezar, hay un grave problema con esa equivalencia que la escolástica dio como hecho inconcuso entre potencia y facultad. "No toda potencia es facultad por el mero hecho de ser potencia - dice Zubiri. Para poder realizar sus actos, no basta con que la potencia sea potencia, sino que necesita estar 'facultada' para realizarlos" (Zubiri, 1998: 90). Cuando se da el caso de que la potencia está facultada por sí misma para producir sus actos, entonces esa potencia es también una facultad. Pero no siempre sucede así; porque hay potencias que por sí mismas no pueden realizar su acto. "Entonces — afirma Zubiri — la potencia no puede producir su acto si no está intrínseca y estructuralmente 'unida' a otra potencia, si no es 'una' con ella” (1998: 90). Para Aristóteles, toda potencia está ordenada a un acto $y$, dada la prioridad ontológica y epistemológica del acto sobre la potencia, es el hombre en tanto

${ }^{8}$ Cfr. S. Teol., I. cc. 77-84. La cuestión 77 inicia del siguiente modo: "Ahora hay que analizar lo referente a las potencias del alma". La versión de la Summa Teológica que citamos trae aquí una nota de la que ahora cito un fragmento: "Vires, virtudes, potentiae, facultataes son la traducción de dýnamis con que se las denominaba en la filosofía griega. Forman parte de las potencias activas, y como tales se contraponen a las potencias pasivas, cuyo máximo exponente es la materia prima; aunque coinciden con ellas en ser principios de posibilidad: posibilidad de acción en aquellas; de recepción pasiva en éstas. En unas y otras su opuesto es la impotencia o imposibilidad (Cfr. Aristóteles, Metafísica, 5 c. 12 [Bk 1019 a 15ss]; S. Th. lect. 14; ib., 9 c. 1 [Bk 1046 a 5ss]; S. Th. lect. 1). La doctrina general de las facultades del alma aquí expuesta [por Santo Tomás] supone un desarrollo amplio y personal de presupuestos aristotélicos". Santo Tomás de Aquino, Suma de Teología I. Parte I, BAC, Madrid MMI, p. 700, infra nota $a$. 
acto el que puede sentir y el que puede inteligir. ${ }^{9}$ En la escolástica las cosas no sólo no son distintas, sino que la estructura se formaliza aún más: el alma, la forma del hombre, tiene varias facultades distintas entre sí. ${ }^{10}$

Siempre significó una dificultad, una vez dada por hecho la distinción entre sentir e inteligir, explicar la unidad de su acto. El problema ha corrido por toda la filosofía moderna: Descartes y todos los empirismos, Kant y hasta el mismo Husserl. Pero la tesis de Zubiri es que hay potencias que están unidas, ordenadas primordialmente, a otra potencia. ${ }^{11}$ "Y es esta unidad, este ordenamiento

${ }^{9}$ Cfr. el capítulo VIII del Libro IX de la Metafísica (1049b1-1051a1). Dice Aristóteles: "Puesto que ya hemos definido en cuantos sentidos se dice 'anterior', es evidente que el acto es anterior a la potencia, quiero decir, no solamente a la potencia que ha sido definida como principio capaz de producir el cambio en otro, o 〈en ello mismo, pero en tanto que otro, sino en general, a todo principio capaz de producir el movimiento o capaz de producir el reposo. Y, ciertamente, la naturaleza pertenece al mismo género que la potencia: es, en efecto, un principio capaz de producir el movimiento, pero no en otro, sino en lo mismo en tanto que lo mismo. Pues bien, el acto es anterior a toda potencia de este tipo en cuanto a la noción y en cuanto a la entidad. En cuanto al tiempo, por lo demás, lo es en cierto sentido, y en cierto sentido, no" (Aristóteles, 1994: 1949b1-12). La pertinencia de esta distinción entre acto y potencia y la anterioridad formal del primero viene dada porque la realidad de la sustantividad humana (acto) es talitativamente una inteligencia sentiente (potencia-facultad).

${ }^{10}$ Cfr. S. Teol. I, 1 q. 78 a1.

${ }^{11}$ Esta tesis de la interdependencia de las facultades seguro que Zubiri la recoge de esa idea que según sus propias palabras en la Respectividad de lo Real "hizo furor en la psicología de fines del siglo XIX y comienzos del XX" (2006: 180): "Ninguna de las llamadas facultades puede producir su acto sin estar formal e intrínsecamente modalizada por los actos de otras facultades... Baste recordar por ejemplo los célebres libros de psicología de Harald Höffding. Pero aún fuera de este nivel de ideas, la propia psicología de Wundt enseñaba que no hay 'estados' mentales, sino tan sólo 'acciones' mentales, y que por tanto todos los estados mentales no son sino modulaciones cualitativas de una acción única" (Zubiri, 2006: 180). 
a otra potencia, la que faculta a ambas para producir su acto: la potencia no está ahora facultada por sí misma para producir su acto. Sólo lo está en su unidad estructural con otra. Entonces las dos potencias constituyen estructuralmente una única facultad. Y esta facultad realiza un solo acto"12 (Zubiri, 1998: 90). Lo que tenemos entonces es que cuando la dýnamis en tanto que potencia está capacitada en y por sí misma para producir su acto es por eso una facultad. Pero se da también el hecho de potencias que están unidas estructuralmente a otra potencia que las faculta para producir su acto que es uno sólo y no dos. Entonces tenemos una facultad estructuralmente compleja, distinta a la primera. "Ninguna de las dos potencias actúa por sí misma concurriendo con su actuación al acto total; esto es, las dos potencias no producen cada una un acto parcial del acto total. Por el contrario, las dos potencias no actúan sino en unidad estructural: no actúan de por sí ni total ni parcialmente, sino que sólo actúan unitariamente" (Zubiri, 1998: 90).

Este hecho de una potencia facultada por otra potencia para producir un solo acto es lo que permite borrar toda distinción dicotómica en el ser humano entre el inteligir y el sentir. El sentir del hombre no es una potencia facultada por sí misma para producir su acto en tanto sentir humano; para ello necesita la unidad estructural con la potencia intelectiva. Lo mismo dígase de ésta. En tanto que potencia intelectiva del hombre está sólo facultada para producir su acto unida estructuralmente a la potencia sentiente del hombre. "Así que las dos potencias constituyen los dos momentos de una sola facultad y de un solo acto" (Zubiri, 1998: 90). Tenemos, entonces, que en el hombre, estructuralmente, su intelección es sentiente y su sentir es intelectivo. La potencia del sentir y la potencia del inteligir se codeterminan como facultad. Las potencias no son concurrentes, sino codeterminantes. Y sólo en esta y por esta codeterminación producen un solo acto. Y el acto real sólo

${ }^{12}$ Las cursivas son mías. 
está en el 'co' de la co-determinación. En el mismo acto están las dos potencias estructuralmente 'unas"” (Zubiri, 1998: 90). En el hombre, pues, poder inteligir y poder sentir conforman una sola facultad: la facultad de la inteligencia sentiente. ${ }^{13}$

Conviene que hagamos ahora una aclaración. Como seres humanos que somos no podemos saber lo que sea el puro sentir en propio, en sí mismo. Podemos hacer analogías y suposiciones de lo que pueda ser el puro sentir animal. Pero son analogías y suposiciones que rebasan lo que el sentir cada vez mío me da. De hecho, Zubiri gasta mucha tinta tratando de describir el puro sentir, tal como sería en el animal. Sin embargo, aquí estamos tratando de mantenernos, cuando menos, en una línea fenomenológicodescriptiva que no puede rebasar los límites del hecho tal como me es dado. Y lo único que se puede decir de la sensibilidad me lo marcan los límites de la sensibilidad cada vez mía, humana en todo caso. Tampoco se puede describir lo que sería el puro inteligir, tal cual Dios o las criaturas angélicas harían, por las mismas razones que aducimos a propósito del sentir animal. El inteligir del hombre es sentiente y su sentir es intelectivo. ${ }^{14}$ Uno está preñado del otro. Al hacer análisis de la inteligencia sentiente se puede llevar a cabo una cierta epojé del momento inteligente para estudiar el momento sentiente, y viceversa; pero será un mero recurso metodológico porque, tratándose del hombre, el único acto es el de una inteligencia sentiente.

${ }^{13}$ Dice Zubiri que detesta la palabra psíquico y que detesta aún más la palabra conciencia (Zubiri, 1996: 267). Es que en el fondo están transidas de esa dicotomía entre sentir e inteligir. La mejor opción es el concepto de inteligencia sentiente porque una es estructuralmente la otra.

${ }^{14}$ Ya Aristóteles en Acerca del Alma piensa que "el inteligir y el pensar, por su parte, presentan una gran afinidad con la percepción sensible: en uno y otro caso, en efecto, el alma discierne y reconoce alguna realidad" (427a19). Pero se trata siempre de dos facultades y como tales se trata de dos cosas diferentes (427b13). 
Con la idea del último párrafo apuntamos ya deliberadamente a otro problema: la facultad que es la inteligencia sentiente es un acto, no dos potencias o facultades, como lo pensó Aristóteles y con él la escolástica y, a su modo, la filosofía moderna hasta Husserl. ¿̨ero no hemos dicho en los párrafos anteriores que la inteligencia sentiente era una facultad? Sí, así lo hicimos. Fue para decir que el sentir y el inteligir no podían ser dos facultades distintas. Que si quería seguir hablándose de facultades, debía distinguirse entre facultad y potencia $y$, en todo caso, hablarse de una sola facultad, la de la inteligencia sentiente. Ahora debe decirse que la índole esencial de la intelección sentiente consiste en ser un acto. Bien cabría preguntar si como energeia o como entelequia. La respuesta es obvia: la intelección es energeia, es decir, no se trata en la intelección de un acto consumado, perfectamente realizado y finalizado como en el caso de la entelequia, sino de un proceso para llegar a la plenitud. La energeia que es la intelección consiste en estar inteligiendo: es noergia, el ergon del nous. ${ }^{15} \mathrm{El}$ hombre es una sustantividad; $y$ uno de sus actos es la intelección. A esos actos intelectivos es, pues, a los que hay que atender para describir qué es la inteligencia sentiente.

\section{c) Indole esencial de la inteligencia sentiente}

La pregunta que ahora debemos hacernos es, entonces, cuál es la índole esencial de ese acto en que consiste la intelección. Se trata de llevar la reducción fenomenológica al acto intelectivo en tanto acto para ver en dónde está su índole más propia, sometiéndolo a la epojé que lo desconecte metodológicamente de su genealogía y de su teleología, para analizarlo directamente en su estatuto de mera energeia: "mi estudio va a recaer — dice Zubiri- sobre los

\footnotetext{
${ }^{15}$ Zubiri afirma que "el noema y la noesis no son momentos intelectivos primarios. Lo radical es un devenir de "'ctualidad', un devenir que no es noético ni noemático sino noérgico” (Zubiri, 1998: 64).
} 
actos de inteligir y de sentir en tanto que actos (katà enérgeian), y no en tanto que facultades (katà dýnamin). Los actos no se consideran entonces como actos de una facultad, sino como actos en y por sí mismos" (1998: 20). ${ }^{16}$

Este es el punto: la reducción fenomenológica permite tratar al acto intelectivo en tanto acto, y describirlo en sí y por sí. La filosofía moderna creyó que la esencia de la intelección estaba conformada por la conciencia: por el darse cuenta del sujeto. Pero esto no es así. La esencia de la intelección no puede ser el darse cuenta de. "La intelección es ciertamente un darse cuenta, pero es un darse cuenta de algo que está ya presente. En la unidad indivisa de estos dos momentos es en lo que consiste la intelección" (Zubiri, 1998: 22). ${ }^{17} \mathrm{El}$ "estar presente" de eso de lo que me doy cuenta en la intelección es anterior al acto reflejo de darme cuenta, de tener conciencia de ello. Lo primero para mí en orden cronológico es que me doy cuenta de, tengo conciencia de algo; pero lo primero

${ }^{16}$ Antonio Pintor-Ramos afirma que "[...] cuando Zubiri advierte que él va a analizar la inteligencia kathéenérgeian y no katà dýnamin [...] quiere decir que va referirse únicamente al acto intelectivo en lo que tiene de formalmente intelectivo, cualesquiera que sean los caminos evolutivos que lo hicieron posible, y cualesquiera que sean los objetos concretos a que se aplique" (1994: 72). Aristóteles, por su parte, dice que este es uno de los dilemas metodológicos que el filósofo debe resolver: si estudiar los actos intelectivos o la facultad intelectiva, si estudiar los actos sensitivos o la facultad sensible. Así lo dice en Acerca del Alma: “[...] es también difícil de precisar si procede investigar primero las partes o bien sus actos, por ejemplo, el inteligir o bien el intelecto, el percibir sensitivamente o bien la facultad sensitiva [...] Pero si se concede prioridad a los actos, surgiría nuevamente la dificultad de si se han de estudiar sus objetos antes que ellos, por ejemplo, lo sensible antes que la facultad sensitiva y lo inteligible antes que el intelecto" (402b10-16). En otro momento dice Aristóteles que antes de decir qué es la facultad intelectiva o la sensitiva hay que definir "qué es inteligir o sentir" (415a19), porque "los actos y las acciones son, en efecto, anteriores a las potencias desde el punto de vista de la definición” (415a19). Zubiri ha optado por la descripción de los actos, no por la definición de las facultades.

${ }^{17}$ Las cursivas son mías. 
de suyo es el estar presente en la intelección de eso de lo que me doy cuenta. El realismo antiguo piensa que los sentidos presentan las cosas a la inteligencia para que ésta las conciba (Cfr. Gilson, 2005: 247). La filosofía moderna piensa que inteligir es darse cuenta. Sin embargo, siguiendo los pasos del más riguroso método descriptivo, Zubiri fija la siguiente tarea: "es menester tomar el acto de intelección en la unidad intrínseca de sus dos momentos, pero tan sólo como momentos suyos y no como determinaciones de las cosas o de la conciencia" (Zubiri, 1998: 22). La intelección se analiza, pues, en dos momentos: $a$ ) en el estar presente y $b$ ) de lo que me estoy dando cuenta. En estos dos momentos la epojé alcanza a "eso que está presente" y a "eso de lo que me doy cuenta" y nos pone frente al "mero estar presente" y al "mero estar-me dando cuenta" como momentos físicos de la intelección. Éste es, pues, el último reducto físico de ese acto que es la intelección. Lo que me está presente y de lo que me estoy dando cuenta son el momento noemático de la intelección que apunta a un alter respecto a la intelección misma. Pero lo que importa primero es el momento noético del cual hemos podido descubrir que es noergia: consiste en el mero estar presente de lo que me estoy dando cuenta. "En la intelección me "está" presente algo de lo que yo "estoy" dándome cuenta. La unidad indivisa de estos dos momentos consiste, pues, en el 'estar'" (Zubiri, 1998: 22). Lo que nombre el verbo estar hace que aquello que está presente en la intelección, y de lo que me estoy dando cuenta, sean uno solo.

\section{Conclusión}

Parece que Husserl divisa la tierra prometida de la razón estructuralmente sentiente desde aquende la rivera del río; pero no se atrevió a cruzar y a penetrarla. Efectivamente, descendiendo por la estructura formal de la razón ha llegado hasta ese su momen- 
to sensible; y haciendo lo propio con la sensibilidad, ha topado con esa sensibilidad secundaria que es también intelectual. Pero ha mantenido la tesis de que la razón primigenia, la razón formal, es esencialmente distinta a la sensibilidad, la cual, en tanto que protosensibilidad, es esencialmente distinta a la razón. Razón sensible y sensibilidad intelectual tienen su punto de contacto en algún momento. Pero es el carácter noético de la conciencia el que califica todo acto intencional. Se requiere echar mano de ese yo absoluto, distinto del mundo, para que abrace a la sensibilidad y la incorpore a la conciencia. El problema de cómo se relacionan la sensibilidad y la inteligencia tiene un punto ciego y oscuro en ese nivel donde se afirma una protosensibilidad sin nada de razón, que sin embargo viene después a ser razón sensible.

Zubiri sostendrá, en cambio, que en el hombre, desde su principio y su raíz, la inteligencia es estructuralmente sentiente y el sentir es estructuralmente intelectivo. ${ }^{18}$ Esto es lo que Husserl no pudo ver porque partió del presupuesto de que sensibilidad y razón son diferentes y se relacionan. De ninguna manera es una exageración afirmar, piensa Zubiri, que toda la tradición filosófica, hasta Husserl, ha conceptuado de modo dualista y dicotómico la relación entre el sentir y el inteligir. ${ }^{19} \mathrm{Y}$ aquí está también la raíz de todas las

${ }^{18}$ Antonio Ferraz dice que "la inercia histórica marca al pensamiento una dirección que es difícil de abandonar. La diferencia irreconciliable entre 'lo inteligible' y 'lo sensible' atraviesa la historia de la filosofía y la condiciona. La valoración y relación de esos dos mundos, su conexión con 'lo que es' —auténtica realidad y apariencia, verdad y error, etc. - se han determinado diversamente, pero la diversidad ha partido siempre, por eso es diversidad, del dualismo inteligiblesensible, inteligencia-sensibilidad, inteligir-sentir. Zubiri denuncia este dualismo como un error original y originario de falsos problemas, y, desde un nuevo punto de arranque, recompone el panorama noológico" (Ferraz, 1990: 67).

${ }^{19}$ Ejemplo preclaro es Kant ya en los inicios de la Crítica de la Razón Pura: “.[...] existen dos troncos del conocimiento humano, los cuales proceden acaso de una raíz común, pero desconocida para nosotros: la sensibilidad y el entendimiento. A través de la primera se nos dan los objetos. A través de la segunda los pensa- 
dicotomías entre lo conocido y el conocer según las variantes que ha tomado a lo largo de la tradición: entre ser y concebir, entre la res cogitans y la res extensa, entre el sujeto y el objeto, etc.

Hemos podido mostrar, por ahora, que Husserl mantiene la dicotomía entre el sentir y el inteligir y que hace grandes esfuerzos por mostrar que estos dos momentos se relacionan "naturalmente"; hemos podido dar cuenta también del camino que recorre Zubiri, mediante la vuelta a la dýnamis de Aristóteles, para mostrar que la sensibilidad y la inteligencia se requieren mutuamente para realizar su único acto: la actualización. Nuestro análisis, por lo pronto, queda incompleto. Nos queda como pendiente mostrar que, en estricto rigor, el carácter estructural de la inteligencia sentiente no es una mera idea metafísica, sino un hecho perfectamente descriptible, tanto desde la sensibilidad como desde la inteligencia.

\section{Bibliografía}

Aristóteles, 1994, Metafísica, Tomás Calvo Martínez (intro., trad. y notas), Madrid, Gredos.

, 2000, Acerca del alma, Tomás Calvo Martínez (intro., trad. y notas), Madrid, Gredos.

Ferraz, Antonio, 1990, "Realidad y ser según Zubiri", en Raices y valores históricos del pensamiento español, Sevilla, Fundación Fernando Rielo.

mos. Así, pues, en la medida en que la sensibilidad contenga representaciones a priori que constituyan la condición bajo la que se nos dan los objetos, pertenecerá a la filosofía trascendental. La doctrina trascendental de los sentidos corresponderá a la primera parte de la ciencia de los elementos, ya que las únicas condiciones en las que se nos dan los objetos del conocimiento humano preceden a las condiciones bajo las cuales son pensados" (2002: 60-61). 
Gilson, Etienne, 2005, El ser y los fllósofos, Santiago Fernández Burillo (trad.), Pamplona, EUNSA.

Husserl, Edmund, 1995, Ideas relativas a una fenomenología pura y una filosofía fenomenológica, Libro primero, José Gaos (trad.), México, Fondo de Cultura Económica.

, 1997, Ideas relativas a una fenomenología pura y una filosofía fenomenológica, Libro Segundo, Investigaciones fenomenológicas sobre la constitución, Antonio Zirión (trad.), México, UNAM.

, 2001, Investigaciones Lógicas 1-2, Madrid, Alianza.

Kant, Immanuel, 2002, Critica de la razón pura, Pedro Ribas (pról., trad., notas e índices), México, Alfaguara.

Pintor-Ramos, Antonio, 1994, Realidad y verdad. Las bases de la filosofía de Zubiri, Salamanca, PUPS.

Tirado San Juan, Víctor Manuel, 2002, Intencionalidad, actualidad y esencia. Husserl y Zubiri, Salamanca, PUPS.

Zubiri, Xavier, 1996, Espacio. Tiempo. Materia, Madrid, Alianza / Fundación Xavier Zubiri.

, 1998, Inteligencia sentiente. Inteligencias y realidad, Madrid, Alianza / Fundación Xavier Zubiri.

, 2006, Escritos menores (1953-1983), Madrid, Alianza / Fundación Xavier Zubiri. 
